THE LANCET, J JNUARY 22, 1887.

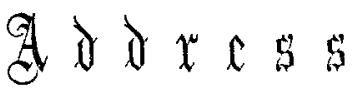

DELIVERED AT THE

fession, for another a vile trade; and in equal contrast it may be a mere useful art practised by one who has neither love nor knowledge of any science, or to the man of scientific mind it may be a thoroughly scientific study as well as an applied science. I could name many living in active practice of whose work a great part is as definitely scientinc as is that done in any other section of biology. $\Lambda$ nd so are the works of many who are gone. For example, I know no reasonable definition of science which would exclude the researches by which Bright attained the knowledge of the disease which bears his name; or which, in a just listory of pathology, would separate, as if they were of different merits, the clinical and the experimental researches from which we have our knowledge of the diseases of arteries and veins. Surely, it would be hard to name a discovery in biology which more deserves the name of scientific than does Jenner's discovery of vaccination; and yet it was made in the plainest practical manner while he was a country practitioner. But, observe, Jenner was a thorough naturalist, trained by John Hunter; and I suspect it will be found that all the best advances in clinical pathology, the best not only in their utility but in their fitness for adjustment among the largest principles of our science, have been made by practitioners who were either by nature or by cultivation men of scientific mind. And it is as sure as anything of the kind can be that similar studies by men of similar mind will still attain as good results.

Practice is full of opportunities for science. Let me suggest only one group of them. Reflection on any day's work in practice may convince us that we have been using a good deal of knowledge or belief which we cannot explain by its relation with other knowledge, whether in pathology or any other branch of science. We may have given what are called specific medicines, or have advised some one in the belief that he was predisposed to some disease, or may have talked of functional diseases. Yet I doubt whether in any of these things there are more than unexplained facts; and if there are not, then we may be sure that the facts are very hopeful beginnings for scientific study by those engaged in practice. I may illustrate this by the example of the use of some of the specinic medicines, such as that of quinine in malarial diseases, of mercury and of iodide of potassium in syphilis, of arsenic in many cases of psoriasis, or of bromide of potassium in some cases of epilepsy. Here are sure facts, practical and useful, as sure as anything in therapeutics. I would not call them scientific, for, so far as I know, they are isolated facts, and separate from what may be called general laws in biology. They are, indeed, the chiof of those facts which, in some minds, bring our clinical pathology into discredit; for, being only useful and not scientific, they are cited as examples of unscientific practice. They are called empirical, and the empiric is deemed equivalent with the quack. Let me say, as in parenthesis, that I think we have here an example of the common fate of words in our language - that if a word acquires a discreditable meaning, its better meaning is gradually lost, and only the worse remains with it. For the empiric and the experimentalist are, I think, synonymous; and yet in pathology the one, having a degraded name, is now deemed a hopeless hindrance to progress, and the other is its hero.

But, however this may be, among these empirical facts modern scientific work in practice may win great riches for pathology. For the medicines I have named are not only remedies, but diagnostic tests; they prove difierences among diseased conditions that in other things appear alike. The epilepsy which is averted by the habitual use of bromide of potassium cannot depend on the very same conditions as that which is not so averted; the ulcer which heals under the influence of mercury cannot be of the same kind as that which looks like it but does not so heal. Thus, as we all know, these medicines are tests; and we may guess that each of them detects the presence of some material belonging only to the disease which it cures. Here, then, is work for the scientific practitioner; he may find the material and more, if he will observe the facts in practice much more minutely, and record and collect them, and bring to bear on them as much light as possible from other sections of pathological science. They will yield more knowledge, and his practice will be promoted to a better title than "empirical." Let me again refer to some facts which I have already mentioned, and which are now accepted in the largest. principles of pathology. I remember that during my apprenticeship, more than fifty years ago, in a post-mortem exami- 
nation of one who had died with dropsy, a young Guy's man cut across one of the kidneys, and said " Dr. Bright, of Guy's, says there is a form of dropsy which is always associated with disease of the kidneys." This was accepted by the practitioners standing by as a singular fact, and nothing more. I should find it difficult to tell now into what, with fifty years of scientific culture, that singular fact has grown. Or, again, could any fact stand more alone than did that of the use of vaccination as first observed by Jenner? And now it may be honoured as the first knowledge attained in all that wide range of pathology in which Pasteur's great work has been done, and to which Power and Klein have lately annexed their admirable discovery of the true source of the milk scarlatina.

There are many more of this group of the facts of which we have better knowledge in practice than we have in morbid anatomy or any other section of pathology. We are sure, for instance, that there are certain conditions which are justly called predispositions to disease; but in what many of these consist we are, I suppose, quite ignorant. There are diseases or disorders which we must be content to call functional, though I suppose none of us would hold that there can be any change in the working of a part without a change in its structure or composition. We know that certain disorders, such as typhoid and scarlet fever, are apt to be followed by certain other disorders, which we call their sequels; but we have not yet shown the changes of which the sequence is a necessary consequence. We know that different morbid conditions may be combined, as in diseases which we may call hybrid or mongrel; we can recognise many of these combinations during life; they are things to be "attended to," as we say, in treating cases; but of the allied varieties of morbid changes of structure or composition, and of the lessons they would teach, we know, I think, at present very little.

How may these defects be remedied? Surely, the best way will be by study and minute scientific work in practice. I say emphatically minute work, for I think it can be proved by the example of other sciences that the more minute the inquiries and the facts obtained by them, the more sure and complete will the fusion of pathology become with the whole body of biological science, and the more will it thence gain.

Now, these more minute investigations may be made not only in the records of clinical observation, which may be far more minute than they are now, but, I venture to think, even in microscopic examinations, especially if these be made whenever it is possible on the living as well as on the dead morbid structures. I would not, in any degree, depreciate the value of the knowledge gained by examining the welldefined structures which are shown in microscopic specimens prepared with hardening and staining and other fixing processes. They ensure a more exact diagnosis, and they may be studied deliberately and with comparison; but while they have all the value, they have also some of the defects, of botanical specimens dried and flattened in an herbarium. These are essential to accuracy in descriptive botany, and to the diagnosis of species and varieties, but the vegetable physiologist must study living things. The herbarium tells little of the true plant-life, and of many processes in which that life is expressed, such as the minute intra-cellular movements and others of the like kind. Things of this kind, and important differences among them, may be found if the method of examining still living tissues can be improved, and if it be the rule to examine each morbid growth or product both directly after its removal from the living body while it may be deemed still alive, and after it has been prepared for repeated examining by staining or other like processes. I venture to expect that by methods such as these, and with improving microscopic power, the sight may often reach far beyond the boundary of what has yet been seen, and will detect differences of structure or of movement in what we are at present obliged to call structureless. And, even beyond this, I would hope that the microscope, with microscopic chemical tests, will detect differences which must be referred to differences of composition rather than of anything that can be called structure, and yet not less decisive of distinctive properties.

But I will not go on thus hoping, and perhaps only guessing. Let me only add one warning suggested by that word "structureless." It suggests the recollection that we are all apt at times to submit to the fascination of promises of finality; to find comfort in believing that we have really reached a boundary; that something is really structureless; or that there is a protoplasm which is the same always and everywhere, at least in the same species; or that in apparently similar substances there may be differences of potentiality; as if in things material there could be differences of power or property without differences of structure or of composition. We should get rid of these idle-making fallacies. The protoplasm in every structure, or of every embryo, must be as essentially different from that of every other as is the structrire or the creature which in due time it may become; and these differences will be discovered by our successors if we-I mean you-do not discover them. And for one caution more. Let us never be content with present utility. Glad of it we may well be, and even proud, for science cannot be degraded by being useful in good things, and I suppose that of all utilities none can minister more happiness to those who most need it than ours may; but we must not be content with it as it is; it will be increased by every increase of our real knowledge.

Letme, before I end, again express my regret that $I$ have been obliged to limit myself thus narrowly in speaking of pathology. Let me repeat that it is only because I have too little knowledge of other methods of study to speak of them definitely or even safely. But I earnestly hope that in our meetings we shall have contributions from them all, for all are essential to the progress of our science, and it will be a singular pleasure to me if, in my office as president, I can promote them. To do so will make my office very happy and very useful to me in helping me to avert that sad defect of old age, the indifference or dislike to the changes which come of the increase of knowledge. One sees that, as men grow old and wish for rest, they are prone to ask, Where are we to stop? I do not know more than this: that we must not stop where we are; we must go on and on, and we may be sure that they who work to find the truth will not work in vainsure that with true work true good will come. So I will hope that it may be here during my presidency.

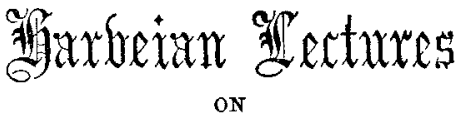

\section{CANCER OF THE UTERUS.}

By J. WILIIAMS, M.D. Lond., F.R.C.P., OBSTETRIC PHYSTCIAN TO UNIVERSTTY COLLEGE HOSPITAL, LONDON.

\section{LECTURE II.}

CANCER OF THE CERVIX.

Gentlemen,- We now pass on to the consideration of cancer of the cervix proper, but before entering upon this part of our subject we must take a rapid glance at a condition which has received a great deal of attention from time to time, and for which many kinds of treatment have been practised, but whose nature remained quite unknown until revealed recently by the investigations of Ruge and Veit. I mean so-called ulceration, abrasion, or erosion of the os uteri. This is situated on the lips of the uterus, on one or on both. It is of a red colour, and in some cases forms a narrow ring around the os; in others it is limited to one lip"; in others, again, it covers an area as large as a florin, and involves apparently the entire surface of the lips. The surface is soft and often corered by papillæ, which bleed readily. The condition is neither an ulcer, an abrasion, nor an erosion. There is no loss of tissue, and the surface is covered by epithelium, but it is epithelium of the columnar kind. The columnar epithelium has encroached upon the territory of the squamous and displaced it.

An erosion may present an appearance rery like that of cancer, and, on the other hand, cancer may appear very like an erosion. In such cases it is not possible to recognise the real character of the morbid process at once except by the microscope. Clinical observation fails here unless ample time be given, and sometimes this is done and the consequences are disastrous in those cases which prore to be malignant, for when time has solved the difficulty it is too late to have recourse to any curative treatment with any chance of success.

What is an erosion? and in what does it differ from cancer 